\title{
A New financial crisis could start again from the USA
}

\author{
Giovanni Antonio Cossiga \\ Presidente Collegio sindaci Policlinico Umberto 1 \\ Università Sapienza - ROMA
}

\begin{abstract}
A new financial crisis could be on the horizon of the global economy. The series of speculative events that flashed since the beginning of the century wouldn't be exhausted. In effect, there are some recognizable similarities with the years of speculative bubble formation during the last decade that can justify all the current concern. But the hypothesis that the cold bucket of all crises has not moved away and could strike again, could be linked to the defence entrusted to monetary and fiscal policy adopted to mitigate the depression strength in 2008-2010. There is no doubt that the ultra-Keynesian policies adopted to ease the bites of the crisis have also started a cycle resumption on both sides of the Atlantic. However, these policies may have left unresolved the correction required by the acceleration of world development, in order to keep under control, the exploitation of natural resources and the survival chances of living beings on the planet. In the case of a possible new speculative bubble, we should not expect a reissue of the 2008-2010 crisis, because the global landscape has now changed. Differently from the past, the big economies are not synchronized. On the one hand, the US economy is expected to accelerate over the next three years. On the other hand, Europe, UK and Japan are slowing down. Moreover, China is still running though with some difficulty: by now, in fact, China has become a global giant and could no longer act as a shock absorber, as in the past, in the face of a new recession coming again from the USA. The desynchronization of the great economies and the expected normalization of the Chinese economy are the different scenario faced by the possibility of a new post-speculation crisis that may arise again from the USA.
\end{abstract}

Keyword: Economic cycle, speculative paradigm, recession, deflation, monetary policy

\section{INTRODUCTION}

The global economy is experiencing a condition of uncertainty, overloaded by contradictory events that are increasing this feeling though without being neither its cause nor its accelerator. The recurring phenomenon accompanying this confused state between depression and boom has been, in the present as in the past decade, the tension supporting the oil prices. The rise in the oil prices, despite the absence of any tension on supply, is not justified by the global economy growth, which seems instead entered a phase of relative calm. In fact, the IMF forecasts for global growth in the two-year period 2018-2019 indicate a cautious deceleration of the development pace, more accentuated in 2019. ${ }^{1}$

\footnotetext{
${ }^{1}$ Global growth is projected to reach 3.9 percent in 2018 and 2019, in line with the forecast of the April 2018 World Economic Outlook (WEO), but the expansion is becoming less even, and risks to the outlook are mounting. The rate of expansion appears to have peaked in some major economies and growth has become less synchronized. In the United States, near-term momentum is strengthening in line with the April WEO forecast, and the US dollar has appreciated by around 5 percent in recent weeks. Growth projections have been revised down for the euro area, Japan, and the United Kingdom, reflecting negative surprises to activity in early 2018. Among emerging market and developing economies, growth prospects are also becoming more uneven, amid rising oil prices, higher yields in the United States, escalating trade tensions, and market pressures on the currencies of some economies with weaker fundamentals. IMF - World Economic Outlook Update, July 2018
} 
The acceleration in the oil prices moves according to a speculative motivation. Just as speculative as the "black gold" rise in the first decade of 2000, which announced the boom and the devastating financial crisis of 2008-2009. In the absence of motivation on the sustained growth perspective, the incongruous flare-up of oil prices is a warning signal about the economy unstable state. Below the surface of an apparent torpor, it's not to be excluded that a new cycle of speculative boom and corrective financial crisis sequence can be revived.

The recurrence of speculative cycles it's nothing new. During the first decade of the 2000s, occurred in sequence the speculation of the so-called dot-com, the sudden rise in oil price that exceeded \$ 150 per barrel, the ultra-speculative tension of the World stock markets, and finally the unstoppable boom in the real estate, powered by the subprime mortgage. A recurrence of speculative cycles can also be found in the 1929 long crisis, apart from the errors on the monetary plan that exacerbated its gravity. After the serious deviation in the early thirties in fact, the GDP line shows a potential recovery until the middle of the decade, unfortunately also built on speculative tensions, up to a very serious fallout at mid-period, from which the world would emerge only at the outbreak of Second World War.

Again, this is nothing new. The speculation-financial crisis paradigm is renewed when the economic system remains unstable for a quite long time. Until to reach the point where the economy doesn't seem to have any other possibility to try to regain a more stable condition, than a false (speculative) growth followed by a heavy depression of the economic cycle. No wonder the way back to stability is so winding. In fact, the instability of the economy can be defined as the attempt to live above the resources that the natural system is providing for the planet life. The balance in the use of resources available for living beings is obviously fundamental, from a perspective moving from the present towards the future of life in our world.

In other words, in the present there must be a continuous parallelism between resources and their use, to safeguard the balance of life on the planet even in a very distant future. Well, it is not surprising that the mechanism ensuring the constant and proper natural correction from abuses in the consumption of resources, in this long-term perspective, is exactly the cycle of the economy.

\section{THE PRECARIOUS BALANCE OF ECONOMIC SYSTEMS}

In a stable economic system, the development pace follows a horizontal profile, with an inclination depending on the potential. The phenomenon of the economy rhythmic trend is instead a sign that instability is increasing and that the correction is in progress through the recessive part of the wave. Examined through the use made of natural resources, the recession is to be interpreted as a consumption braking action. In other words, if the consumption is excessive, the economic slowdown caused by the recession basically should balance the natural resources and their compatible use.

Safeguarding the future, even very far away, of the planet and its resources for the life, in the case of improper or excessive use of the available resources, seems to be entrusted to a natural correction mechanism. A natural tool, even traumatic and sometimes socially severe in the present, which aims to safeguard the balancing of resources that reached the compatibility limit.

It's reasonable therefore, to think that the intensity of the recession or depression in the economy is an index of the correction in progress. According to this point of view, the winding procedure of a false speculative growth followed by heavy depression of the economy as well 
as its recurrence are all to be considered as an extreme corrective mechanism, naturally activated to mitigate a prolonged and not reversible instability of the economy. A serious present damage is imposed just to avoid a heavier impact on the life projection in the future, no matter if far away.

According to this argument, the possible recurrence of a series of speculation-depression sequences is always the bitter result of the behavior of institutions, companies and families in the management of the current situation. Therefore, the fall into the speculative vortex or the possibility to remain at the edge of precipice, without falling, is always firmly in the hands of institutions, companies and families. As saying that, even in economics, destiny is not written because we're writing it all of us day by day with our collective behavior.

Now it's clear that a repeat of the speculative cycle and the subsequent correction of the economy are causing some concern for institutions, companies and families, so much to suggest, as a tautology, some preventive maneuvers. Unfortunately, in the current condition, we are not able to predict and promptly assess an economy morbid state feeding speculative cycles.

This weakness in the prediction of the ongoing speculative damage unfortunately is somehow due to the own corrective mechanism. It should be remembered that, following the compatibility objective regarding the use of the planet's resources, the natural correction system could put some real traps just in order to reach its irrevocable goal. That is, to spread around a sort of fog reducing the capacity of communities, companies and individuals to perceive the real state of the global economy. A strange general apathy in decoding the real state of the economy that can be considered as a reassuring message, which is propaedeutic and functional to the deceptive acceleration of the economy: what is essentially the speculation.

In other words, the collective fall of attention to risk is like a siren song emerging from the market, synthesized in a subliminal form. There is a widespread feeling that the economy can grow without limits, although this way of feeling would conflict with the real state of the economy and with the past experience.

We should consider that, under conditions of normal or almost stable system, also the man in the street shows an indirect but fully coherent knowledge of the economy state. The next-door family has, like all of us, a maybe synthetic but effective knowledge of the economy state in the country. The society, in turn, shows to recognize and even promote these precognition faculties that institutions, companies, individuals and the community show they have in recognizing the economy state, both currently and in the near future.

A fundamental attestation, because it's justifying and giving meaning to the value of democracy or to the importance of citizen participation in the definition of what are the common good and the good governance. This widespread perception is generated because the market provides continuous indications in direct terms easy to understand about market prospects, such as prices, unemployment trends, cost of living, wages, etc.

Since the knowledge degree on the economy state in individuals and communities is reliable, although synthetic and essential, it seems reasonable also to consider that the market provides, next to the values immediately perceivable, some implicit sensations on the economy state that are contributing to form the common opinion. These widespread sensations conforming the opinions of the man in the street are not only the synthesis of direct perceptions through the 
market events, but go further, so becoming the basic substance for a synthetic but coherent evaluation of the economic prospects for each component of the society.

In short, the synthesis between the direct perceptions coming from the market, accessible to anyone, and the collective sensations summarizing the economy general state, can be able to provide each member of the society with a sufficiently updated knowledge about the current state of the things in economy.

In a condition of normal economy, this collective assessment about the economic system situation is able to generate an optimistic view that guarantees a parallel course between the relatively good state of the economy and the perceptions that individuals, institutions and companies do actually have. This parallel trend between the community prediction and the economy strength is fundamental also at the social level. In fact, it's providing the sustainable and solid basis to affirm the primacy of democracy, interpreted as a people choice compared to the non-democratic social models.

Everything is alright if the economic things are walking on a relatively stable ground, or rather on growth prospects somehow satisfactory and above all compatible. In this favorable situation, the collective sentiment of citizens, companies and institutions seems to be coherently aimed to confirm the status quo. Therefore, is prevailing the collective feeling that the best government in the future would coincide with the one currently in charge. In any case, during the electoral campaign the future projects and programs of the competing parties, are compared. Provided that we are in a condition of relative calm for the economy, therefore, the collective perception must be considered as the best strategy able to select the government that is considered the best in order to manage the economy in the next legislature.

This relatively idyllic picture, which promotes the democratic contexts against others that are not, may show some cloud, though temporary. In the sense that the observed parallelism between the economy state and its perception by the individuals could suffer, in a transitory way, a more or less marked discontinuity. The problem can be caused by the deviation that the collective feeling about the economy state could suffer in the case of a prolonged disruption of the economy situation.

Inside a long time unstable economy, the need for a natural correction of its direction can deliver within the community - intended as institutions, companies and individuals - the unusual feeling that the economy has entered an illusory era of growth without limits. This widespread feeling can produce a general relaxation of the attention to risk among companies and families.

This is a context soon becoming favorable to the development of a speculative boom, followed by an unavoidable financial crisis. On a general level, this means that an economy can be troubled by unexpected crises, with costly implications for the whole social organization.

In a context of natural correction of instability, therefore, an anomalous collective assessment can be created about the economy which could therefore be reflected on the social organization, which in parallel may suffer some estrangement effect. As saying that the economy factor is prevailing over the social order, which therefore is affected by its alterations. The economy shows to prevail because of the hidden imperative of the future conservation of resources. Thus, a distorted evaluation of the collectivity about the economy state during the boom time with the subsequent astonishment due to the society general impoverishment 
caused by the economy depression, may also affect and alter the collective capacity of democratic societies to select a good Government during the electoral round.

Just to say that the extended alteration of the economy can also affect and impoverish the collective capacity of society to correctly understand the economy state to be able to assess, in synthetic but reasonably clear terms, a program for the good governance of public affairs. It follows that long-term problems in economics could consequently also tarnish the specific capability of the communities to choose the good government program on the occasion of the electoral round.

This occurred difficulty in selecting a good governance, represents for democratic countries a potential further hesitation on the road leading to the restoration of stability in the economy. Those leaderships born under the umbrella of the economic crisis may not be able to follow the path to economic recovery, due to their political weakness and poor programs. The unexpected result may be exactly the long chain of pale conjuncture and recessions accompanying fragile countries, in the event of global scenarios with potential speculative bubbles.

\section{INFLUENCE OF US POLICY ON THE MARKET TRENDS}

Well, at this point the question arises how, during the speculative bubble development, the sappy horizon of an improbable growth without end could be sustained and become reliable. The apparently "quiet" condition of the economy provides an ambiguous framework to assess the excited real state of the market. During the speculative phase, the growth of the economy remains generally contained. Well, just this apparent calm, before the storm in the economy under shock, seems to be the social anesthetic validating the collective distraction from the real risk. According to this point of view, the current picture of the global economy doesn't seem to be free from all worries.

According to the IMF, in the three-year period 2018-2020 the growth of the US economy averaged 3\%; in Europe it stops at 2\% or even less. For the following two-year period 19211922, the IMF forecast reduces the performance on both sides of the Atlantic until an average of $1.5 \%$ or below. ${ }^{2}$ For the next few years, therefore, the economy in the main industrialized countries appears to be a relatively calm sea, which doesn't lead us to believe as possible the formation of speculative waves. And yet, this false tranquility could hide the formation of a new speculative wave.

On the other hand, it is not surprising that in this context the Central Banks on both sides of the Atlantic show a singular proximity of views about the inflation rate. In various statements made by the main Central Banks, it is argued that the nominal price profile seems to delay compared to the economy pace. Moreover, the quite tonic economy in the USA has recently been pushing the increase of the inflation rate. ${ }^{3}$

\footnotetext{
2 In the United States, near-term momentum in the economy is expected to strengthen temporarily in line with the April WEO forecast, with growth projected at 2.9 percent in 2018 and 2.7 percent in 2019 . Growth in the euro area economy is projected to slow gradually from 2.4 percent in 2017 to 2.2 percent in 2018 and to 1.9 percent in 2019. The growth forecast for Japan has been marked down to 1.0 percent for 2018, The economy is expected to strengthen over the remainder of the year and into 2019, aided by stronger private consumption, external demand, and investment. IMF World Economic Outlook Update, July 2018

3 The US inflation rate "preferred" by the Fed - equal to the price of consumer spending - has just touched the $2 \%$ target. But other parameters are growing even faster. The overall consumer price index is more than $3 \%$ higher than a year ago. The "basic" consumer index also increased by $2.4 \%$ over a period of one year.
} 
Well, it doesn't seem disputable that the delay of the inflation rate may be an anomaly. It should be noted, in fact, that the deflation tendency of the economy often accompanies the slow formation of speculative bubbles. It should be considered also that an increase pushing the inflation rate near the base inflation close to $2 \%$ could mean the exit of the economy from the paralysis of the tendential deflation. But not only that. It can hide indeed also a danger. The proximity of prices to the base inflation of $2 \%$, especially if and when this limit is exceeded, may not be a sign of escape from the low inflation tunnel, simply because the economy remains unstable. In this case, the tension in prices exceeding the basic inflation cannot be attributed to the normalization of the economic situation, but rather to the internal tensions within the prespeculative economy.

We have already observed (Cossiga, 2018) that the climate of prolonged instability can have some effects, as well as on the economy side, also on the social relations. In fact, a propensity favorable to the formation of speculative bubbles also brings a potential, attenuated capability of the community to select programs and governments suitable for the good management of public affairs. In this way, from the social plan we're returning again to the economy, with further time delay in the system instability adjustment.

This fall in collective sensibility seems to be connected also to the climate of relative irresponsibility that is generated due to an extended instability of the economy. The natural mechanism that seems to attenuate the risk attention of the operators, seems to be the same affecting the community intuition, when called to democratically choose the political leadership.

The objective of the natural mechanism is always the same: to respect the imperative to safeguard the resources for living beings in the future. This imperative can impose a serious economic and social damage in the present, though to avoid a much more serious future damage to the balance between natural system and humans on the planet. In other words, the objective that aims to achieve the natural correction strategy, all in all, it's the slowdown of the economy cycle to reduce the use of resources, which instead the activity acceleration can put in a dangerous tension.

At this point, it must be added that if the global economy is under the threat of a new speculative phase, it does not seem unavoidable that the process would continue until the final crisis. In fact, it is possible to admit that interruptive actions of the process may take place, therefore allowing the system to initiate the required natural correction in advance.

In the hypothesis of a premature interruption of the speculative cycle, the sequence remains just the same, with the fall of the economic system into a corrective financial crisis. However, it can be argued that the economic and social damage to the system is nevertheless contained, because the continuation of the speculative cycle until its natural end is so avoided. That continuation, in fact, would have required a more severe recession to eliminate the greater share of virtual economy produced by the speculative process.

Remaining in the hypothesis that the cycle of the global economy is building a new speculative crisis, the eventuality of a premature interruption of this adverse cycle seemed possible to be realized even recently. At this point, let us allow a brief premise. The US presidential elections do have some unique aspects. President Trump wins the competition with Hillary Clinton, wife of former President Bill Clinton, although the Democratic candidate has accumulated a total of votes much higher than the opponent. The Republican candidate himself was not considering 
his success as probable, as clearly came out from the confessions made by the journalist Michael Wolff (Wolff, 2018).

President Trump is now sitting in the White House from January 2107, after the Democrat Obama, a successful politician, black, with great dialectical skills. During his presidency, America emerged from the troubles of the 2008-2010 great financial crisis. Afterwards, America chooses as President a businessman without any previous experience in politics, who moves on the geopolitical quadrant with determination, but also with some naïveté.

After a brief 'honeymoon period' marked by the gains of the Stock Markets not only in the USA, the new presidency has gradually put in place the political program that ensured its success. In keeping with the reaction of the Stock Markets, the uncertainty of the markets caused by the launch of the President's program produces a sharp reversal of the US stock markets, after a long price increase that had reached and exceeded historical levels.

The Figure 1 shows the Dow Jones' trend from August 2017 to July 2018. The rapidly increasing profile of the quotations reaches a maximum (26616) on January 26, 2018; then declines sharply in the following month remaining uncertain on the trajectory to follow. Please note that in February 2007 the Dow Jones had reached a quotation of 13895, and then declined under the blows of the severe financial crisis. Since then the maximum US index prices have reached the new highest records until January 2018.

Figure 1 - Dow Jones Industrial Average from August 2017 (21162) to July 2018 (24870)

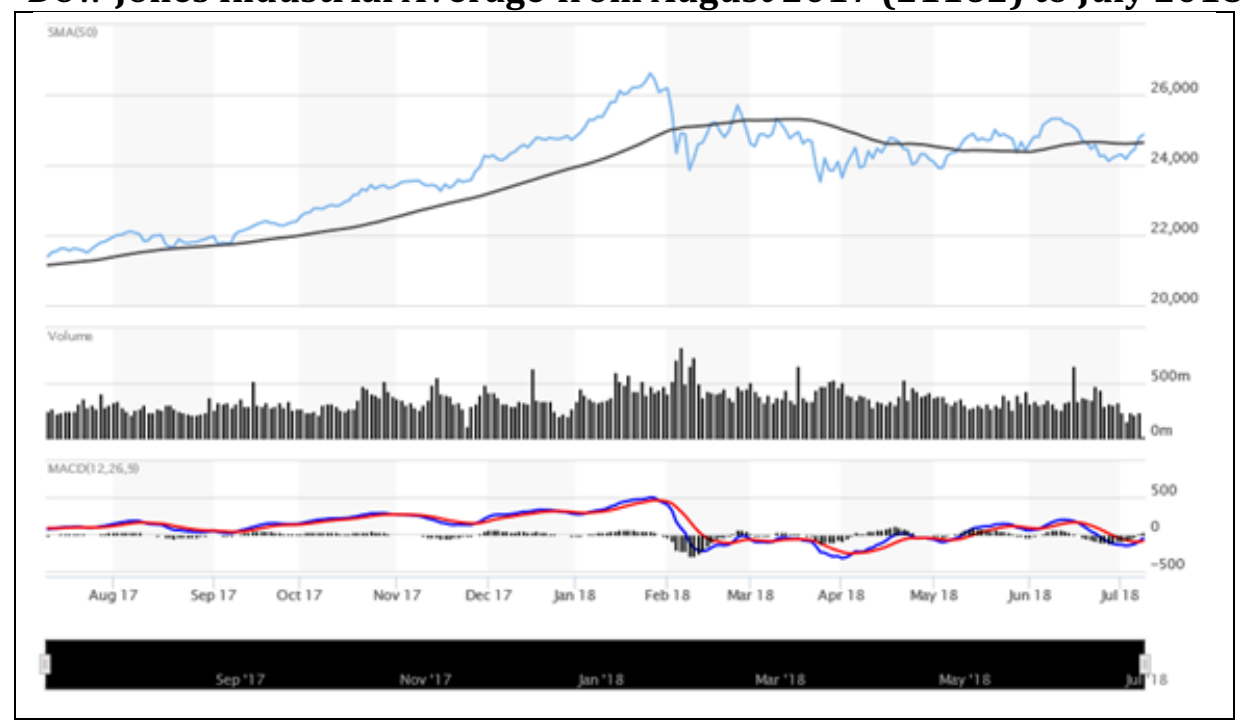

From financial information on MarketWatch website 
Figure 2 - Shanghai Composite Index - From August 2017 (3203) to July 2018 (2891)



From financial information on MarketWatch website

The unopposed increase until January 2018 of the maximum US Stock Market isn't reflected in the performance of the real economy, which during the previous five years traveled at an average of $2 \%$ per annum. The exploit of quotations in the US territory seems rather an indication that the speculative tensions have been dampened by the 2007-2009 financial crisis but remained unsolved. So, they reappeared perhaps more impetuous. However, we should reflect on the sharp quotation drop in February 2018, which affected the global stock markets but with a greater strength in the case of the Chinese Stock Exchanges (Figure 2).

The worldwide sudden reversal of stock exchanges is a sign of all the uncertainties and misunderstandings of the financial market for the initiatives, partly unexpected, of the American President. Since January 2018 duties have been imposed for the imports into the United States, a renegotiation has started within the NAFTA and moreover new duties have been imposed in trade relations with China. ${ }^{4}$ Last but not least, the decision to exit from the Paris Treaty on Climate. Apart from the motivation, these decisions seem to be able to alter the whole world trade order.

The correction of quotations in the main US Stock Exchanges, however, was a healthy though temporary break. The Dow Jones recovered during the summer the maximum levels recorded in January 2018. Apart from the ups and downs of Stock Markets in the US territory, from our point of view it's important to note that the unexpected innovations have in the meantime undermined the progression - otherwise out of control - of the major Stock Exchanges worldwide.

As saying that the impact on trade and on the world economy of the initiatives started by the US Presidency stopped, at least temporarily, the speculative run of the Stock Exchanges at the global level. Basically, an action has been started to correct the excessive momentum of financial quotations. The excess in stock market values has thus somehow cooled, acting in advance of the natural correction, indeed dampening its force. Therefore, the real hypothesis is posed that unexpected initiatives from the market can mitigate the otherwise unstoppable speculation run.

${ }^{4}$ New tariffs are scheduled for September 24 on $\$ 200$ billion worth of Chinese goods by Washington and over 60 billion of made-in-China products in the USA. 
The problem to be analyzed regards the possible effects of partial corrections that are started by government initiatives, within an economy scenario prone to the formation of speculative bubbles. Above all I would say, in case there would be a risk of resumption of a speculative rise, as it seems probable in present circumstances. It should be added that the possibility of an interruptive correction during the formative cycle of the bubble - probably unforeseen in this case - doesn't seem able to solve the economic system instability. It is not a panacea, therefore, for the return on the road towards compatible growth. However, the sudden 22change in policies leads to a reversal of the over-excited economy, which appears to be able to block the growing of a speculative bubble. The consequences of this temporary block are to be evaluated, though certainly not in negative terms.

In this case, it should be considered that various actions are taking place at government level, such as the change in world trade policies, which have shown the capability to hinder the speculative bubble emphasis at the global level. At this point it seems useful to recall what has been said in a previous essay (Cossiga, No. X, 2018), where it has been argued that the danger of falling in the speculative wave can only be avoided if the global economy pace would tend to slow down in the next years, by the way according also to the IMF forecasts on the economy growth in the next two-year period.

This favorable forecast on the world economy fate may be contradicted. Above all by actions of fiscal and monetary policy that can have a contrary effect, then toning the speculative emphasis. The 2017 Tax Act signed into law by President Donald Trump on December 22nd, 2017 went into effect on January 1, 2018 and will not affect 2017 taxes. This is a sort of "bill" that has a propulsion effect on potential growth and accelerates the formation of public deficit and debt over the next decade. ${ }^{5}$

On a general level, the push of fiscal policies on the US economy trend seems to have an opposite effect, I would say a balancing effect, regarding the US Presidency policies on the redistribution of the global trade. Basically, the protectionist policies made by the USA have curbed the speculative emphasis of the world Stock Exchanges and, consequently, have calmed the impulse of a morbid conjuncture.

In fact, during the first quarter of 2018 the phenomenon of the speculative bubble formation has temporarily entered a stalemate. Nevertheless, just a few months later, the cautious picture seems to have changed in the USA. With the Tax Act entry, which has a propulsion effect on the income of companies and households, the growth engine has increased its strength and could run beyond its normal potential for a whole three-year period. With the fiscal maneuver, it's canceled or mitigated the dampening impact of measures on the world trade: those measures

5 “In CBO's projections, the effects of the 2017 tax act on incentives to work, save, and invest raise real potential GDP throughout the 2018-2028 period. In addition, all three major laws mentioned above provide fiscal stimulus, raising real GDP more than potential GDP in the near term. ...

In CBO's projections, real GDP expands by 3.3 percent this year and by 2.4 percent in 2019. It grew by 2.6 percent last year. Most of the growth in output in the next two years is driven by consumer spending and business investment, but federal spending also contributes a significant amount this year. After averaging 1.7 percent from 2020 through 2026, real GDP growth is projected to average 1.8 percent in the last two years of the 2018-2028 period....

As deficits accumulate in CBO's projections, debt held by the public rises from 78 percent of GDP (or \$16 trillion) at the end of 2018 to 96 percent of GDP (or \$29 trillion) by 2028. That percentage would be the largest since 1946 and well more than twice the average over the past five decades." CBO's Budget and Economic Outlook for 2018 to 2028 
that, even in the American territory, make it quite difficult to assess their consequences on production activities highly integrated at the global level.

There could be a risk, however, for the United States in the new run. In the context so excited, the preconditions for a real income growth would not be created, but rather there would be a virtual acceleration of the economy that could be cancelled by the depression contained in the speculative paradigm.

We can therefore wonder what potential consequences on the global economy could have the stop and go of the speculative process suffered by the US economy, under the contrasting effects of government acts and legislative measures of different sign.

\section{POTENTIAL EFFECTS OF THE US ECONOMY CONTRASTS ON THE GLOBAL ECONOMY The development synchrony breakup between the two sides of the Atlantic}

These light \& dark effects of the US policies were reflected in the growth rate, which in the first quarter of 2018 stood at $2 \%$ per year, a slight decline compared to the two previous quarters. There has been a double weak slowing down in household consumption and in real estate sector investments. From the second quarter, however, the business cycle slightly recovered for the fiscal benefits and the public investment program decided by the Trump administration. 6

Estimates are now suggesting that the sum of the rise and decline pressures expected in the USA would be resolved in a development acceleration, during the next three years from 2018 to 2020. This hypothesis also seems to be confirmed by the unemployment level, now stable at $3.9 \%$, and in a further downward trend. Although the employment figure is just a delayed factor, therefore reflecting the past economy state, with only partial reflections on its future behavior.

This two-faced climate, which anyway seems to launch the USA towards a more sustained growth in the three-year period 2018-2020, however doesn't find any confirmation on this side of the Atlantic. The latest ECB projections for the growth in Euro area, indicate a slowdown from $2.4 \%$ in 2017 to $1.8 \%$ expected for 2020 . These are estimates that presumably are only partially updated, in relation to the effects on world trade of the protectionist policy of the US Presidency. ${ }^{7}$

It should be considered also that the acceleration recorded in 2017 inside the euro area and by the 27 Europe is due partly to the boost coming from exports, which accelerated towards the USA and China. This economy component of the area is destined to contract during the next three years, and not only for the problems introduced in the world trade. Therefore, a gap is emerging among the Western economies, with the USA riding the economic situation trend, so

\footnotetext{
6 "The top-earning 1 percent of households — those earning more than $\$ 607,000$ a year — will pay a combined $\$ 111$ billion less this year in federal taxes than they would have if the laws had remained unchanged since 2000. That's an enormous windfall. It's more, in total dollars, than the tax cut received over the same period by the entire bottom 60 percent of earners, according to an analysis being published today. ... By David Leonhardt - New York Times July 11, 2018

${ }^{7}$ Quarterly real GDP growth moderated to $0.4 \%$ in the first quarter of 2018 , following growth of $0.7 \%$ in the previous quarters. This moderation reflects a pull-back from the very high levels of growth in 2017, compounded by an increase in uncertainty and some temporary and supply-side factors at both the domestic and the global level, as well as weaker impetus from external trade. ECB - Economic Bulletin - Issue 4/18
} 
cumulating an average annual growth even higher than 3\% in the three-year period 20182020. At a slowing pace instead is going the euro area, though growing anyway. ${ }^{8}$

This speed change of economic dynamics between the USA and Europe doesn't seem meaningless. The focus always goes to the speculative emphasis that remains inside the global economic systems' DNA, especially when pushing the speed acceleration button for the markets, as in the case of the United States. In any case, the forced acceleration of the development pace remains the primary signal of the economy relapse in the speculation spiral. Thus, it is evident the importance of the presence or absence of this heterodox signal inside the perspectives of economic systems.

As saying that the breaking of the global development synchrony, with an accelerating America and a slowing Europe, indicates that synchrony will not be renewed during the coming years. The same synchrony of the whole economy that from the beginning of the decade has dragged the global economy into a speculative whirl, starting from the United States. In this new scenario of the global economy, the potential effects of a new speculative event, again starting from the US economy, are all to be evaluated.

As can be seen from Figure 3, in the first decade of 2000 the main economies at a global level were going in full synchrony. The virtual acceleration of speculative development is a disease embracing the entire world economy, which then fell again as a whole into the heavy financial crisis of 2008-2009.

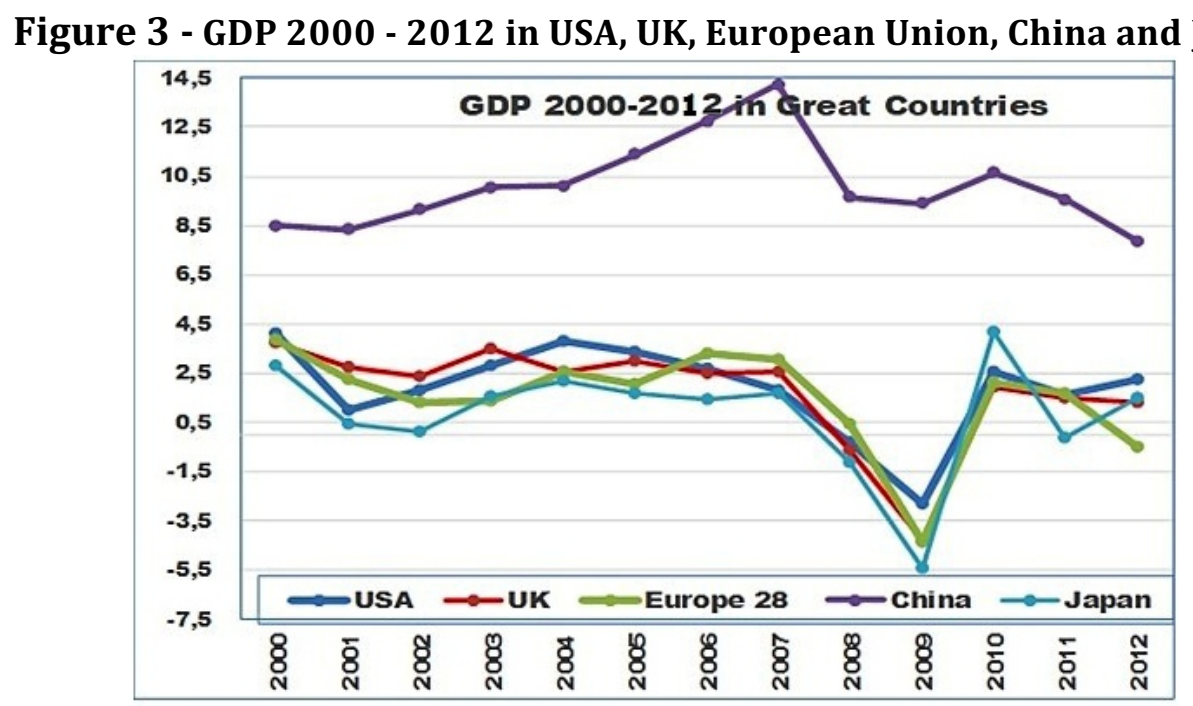

Elaboration on OECD data

\footnotetext{
8 "This assessment is broadly reflected in the June 2018 Euro-system staff macroeconomic projections for the euro area. These projections foresee annual real GDP increasing by $2.1 \%$ in 2018, $1.9 \%$ in 2019 and $1.7 \%$ in 2020. Compared with the March 2018 ECB staff macroeconomic projections, the outlook for real GDP growth has been revised down for 2018 and remains unchanged for 2019 and 2020." Press Conference Mario Draghi - Riga, 14 June 2018

"Growth in the euro area economy is projected to slow gradually from 2.4 percent in 2017 to 2.2 percent in 2018 and to 1.9 percent in 2019 (a downward revision of 0.2 percentage point for 2018 and 0.1 percentage point for 2019 compared with the April WEO). Forecasts for 2018 growth have been revised down for Germany and France after activity softened more than expected in the first quarter, and in Italy, where wider sovereign spreads and tighter financial conditions in the wake of recent political uncertainty are expected to weigh on domestic demand." World Economic Outlook Update, July 2018
} 
It should be noted that the breakdown of the development pace synchrony between the two sides of the Atlantic is enhanced by the strategy of the US Presidency, which aims through protectionist policies to encourage the domestic economy to the detriment of commercially enemy countries, Germany and China first of all.

Apart from the considerations on the effectiveness of this strategy, which is anyway incomplete and improbable, apparently it seems to benefit the country, according to the motto America first, to the detriment of the community of all the others. The synchrony breakdown in the development pace of the main actors of the world economy is based on the hypothesis that, for the next two or three years, Trump's America would run at an average annual rate of 3\% and even more, while the sister countries of this side of the Atlantic would proceed at an average pace just slightly above the half. This fate seems to be shared also by Japan.

But there is indeed an adverse side of this pro-development option. In fact, the desynchronization of economies can lead to an isolation of the North American economy, so that a speculative acceleration in the American territory wouldn't be shared by Europe, Japan, nor by the Middle East and Southeast Asia countries, which could all escape that negative fate. A corrective event of the unstable economic trend, according to the speculation-recession paradigm, is always accompanied by a strong sectorial excitement of the economy. Without this assumption, it seems quite unlikely the process starting, even indirectly.

\section{The role of the Chinese superpower in the current global scenario}

A different fate may concern China. As can be seen from Figure 3, this Asian country recorded the greatest acceleration during the years 2004-2007, and then decelerated while still maintaining a giant development pace. For the next three years, according to the scenario described above, we can suppose a slow decline in the development pace of the Chinese economy, until an average of $5 \%$ or less. In this regard we can read the signs of a more cautious development of the Chinese economy in the coming years, just looking at the recent trend of the Stock Exchanges, which generally anticipate the economic values. In particular, the Shanghai Stock Exchange from a maximum of 3559 in February 2018 came down to 2891 in the following July, under the blows of US protectionist policy.

It is interesting to note that the Chinese economy, during the severe financial crisis of 20082010, suffered only a cautious and gradual decline in its growth rate. A trend that has stabilized in the current decade, then staying at around 6\%. Therefore, a further gradual attenuation is expected for the next three years. The slow decline towards compatible levels of economic development in China represents an important step in the normalization of the world economy going towards development models in harmony with the natural evolution project.

The fact that China didn't suffer, during the financial crisis of the first decade, a recession comparable to that suffered by all the rest of the world economy, cannot prove that the Chinese economy is, at the time as even today, relatively stable. It's an unlikely hypothesis, in fact, given the speculative over-excitation risks present in a reality that ran all the way for two decades on the path of economic development.

Thus, it cannot be excluded that the Chinese anomaly could constitute a potential overexcitation inside an economy without a showdown. An anomaly made possible by a sort of isolation that has partially preserved the great Asian country from the storm which involved instead most continents. Isolated, because little involved in the sudden eclipse of development 
during the severe financial crisis of the global economy. Certainly not isolated for what concerned the commercial relations that have seen instead China among the great players.

As saying that the Chinese case has probably acted as a spare wheel for the global economy, to mitigate the impetus of the recent global financial crisis. First, for its help to mitigate the consequences of general decline in income and of increasing poverty due to the huge widespread of low-cost Chinese exports. At the same time, the crisis impact on the productive sectors within the industrialized world has been limited by the relocation to China, to reduce costs and then as a reaction to the global recession wave.

In any case, a repetition of the phenomenon that has affected the Chinese and world economy during the financial crisis of the last decade, does not seem possible. There wouldn't be any more the conditions so that China, a world superpower, could play the role of a clearing house in a possible next global financial crisis.

Actually, the controlled price effect on the global market prices was fully deployed with the Chinese export spread of low-cost (and low-quality) products. It is therefore possible that this deflationary effect is now exhausted and being overtaken by the technological direction of the current Chinese production. Furthermore, the process of relocation to China is now mature and slowing down, because of the income and cost of living increase in China. About ten years after the burst of the speculative bubble, new phenomena are now increasing, such as the backshoring or the production relocation in different areas.

The role of superpower conquered by China, during all these years of endless development, is therefore suggesting that, unlike in the past, the economy of the Asian country may suffer the bites of a crisis, this time comparable to that experienced by the most industrialized countries. A strong reaction for the Chinese economy, for decades immune from the phenomenon of the economic cycle reversal. A reaction that could be caused by the instability accumulated by the economy in its long run, so starting finally the continuously postponed showdown. ${ }^{9}$

Remaining on the topic under consideration, we should never forget the critical issue of the giant size of Chinese banks. According to the criterion of total assets, four big Chinese banks are in the top five positions in the world rankings. At number one the "Industrial and Commercial Bank of China", with 3.343 billion euros of assets. The big Chinese banks have a good capitalization while the credit management is quite careful about the risk. We could wonder, however, how they will react to a possible sudden decline in the economic situation, after the high growth of the domestic market for over twenty years has influenced its exceptional development.

\footnotetext{
9 The ten Chinese banks examined in the survey (2007-2016) are almost entirely attributable to control or dominant influence of the state (only one is entirely headed by private capital).

The composition of revenues is peculiar because they come, in the period average, for $80 \%$ from the interest margin and only for $19 \%$ from net commissions, leaving a marginal role to the result of the trading activity. Even though their composition was not very diversified, revenues recorded an average annual growth rate of $13 \%$ from 2007 to 2016: in comparison, Europe, the United States and Japan showed, on the whole, a much more modest + $0.4 \%$.

The level of capitalization at the end of 2016, equal to 7.3\%, is higher than that of European and Japanese banks (respectively $6 \%$ and $5.3 \%$ ) and lower only to that of US banks (11.4\%). Conversely, with a multiplier of 13.8 , the "leverage" is lower than in Europe and Japan, but higher than in the United States. Ufficio Studi Mediobanca - DATI CUMULATIVI DELLE PRINCIPALI BANCHE INTERNAZIONALI COffice of Mediobanca Studies - CUMULATIVE DATA OF THE MAIN INTERNATIONAL BANKS)
} 
All the above to say that the global landscape has changed during the last decade. An eventual fallout of the global economy in the spiral of recurrent speculative cycles, therefore, could have different outcomes and proportions than in the past. It shouldn't be forgotten that the underlying reason for the development of speculative movements and financial crises is rooted in the unstable relationship between economic development and the availability of resources over time.

According to the irrevocable relationship between consumption and availability of resources for the life development on the planet, it can be argued that the thesis formulated by the Club of Rome in the sixties would not make sense nor would be acceptable. According to the paradigm on the availability of natural resources for humankind, it would be improper the hypothesis suggested by the Club of Rome of a potential sudden break between the oil availability and the consumption trend. That is, the trend in oil production would not be able to satisfy the progressively growing demand. A critical hypothesis indeed, overtaken however by the experience of these years and by the development of alternative technologies, which questioned the correlation between consumption and availability of resources. It was thus placed in doubt a fundamental link in the relationship between the environment of our planet and the life nourished and protected by the same planet.

That being said, the fact remains that a positive thinking about the medium-term prospects for the global economy could be a real ingenuity, because the balance between the two factors availability and consumption of natural resources - is also made complex due to greed and selfishness afflicting mankind. Now this balance needs anyway to be reconstructed, although not in the short term. Turning then our attention to the potential presence of waves crossing the global economy is certainly not a mere exercise.

Since the last century, the global economy is crossed by recurrent cycles of speculative excitement that are recomposed when the economy cycle falls into a severe depression. The World War and the long reconstruction season have essentially stemmed these waves that periodically shake the global economy. But they reappeared in the scenario of the two thousand years, with an extension to the entire global economy. Moreover, processes of speculative acceleration and fall of the markets when the excitations turned off: the human history is littered with all this.

The development acceleration serves as an incubator of speculative bubbles, from the tulips' bubble (1634) to the South Sea Bubble in England (1720), to the bubble of the Union Générale in France (1882), up to the so-called Panic of 1825 again in England. The concern for the speculative bubbles moves to the emerging US economic development, starting with the socalled Panic of 1792 on the equity securities owned by the Bank of New York, up to the explosive bubble of 1929. The speculative sequence then will involve the exceptional growth of Japan during the post-World War II in the 1990s, to hit finally the US economic power in the 2000s.

This birds' eye examination of the great speculative bubbles that crossed the recent history is demonstrating that the starting factor is the pressure exerted by a strong growth in economy. A phenomenon common to the great speculative events is the relative blindness catching individuals and companies, when facing a phenomenon that wouldn't have any justification in the real economy. Yet, once started, it leads to widespread losses and severe recession in the economy. These are repetitive and abnormal phenomena that do not have a direction by groups or power centers but are coming from the behavior of an entire community, which is somehow altered by a siren song. 
The hypothesis that this would be a sort of natural reaction to a derailment of the economic system from stability (intended as the human development compatibility compared to the environment evolution), finds a reasonable basis for its credibility. But the natural orchestration guiding and controlling the development of humans and generally of life on the planet doesn't stop certainly at this extreme point: that is, the speculative wave as a reaction to the deviated development. In fact, the same cyclical movement that excites the economy affair is just a natural energy predicting the instability state of economic systems.

The correction to a wrong or excessive development rhythm, compared to the life evolution on the planet, follows a mechanism that is always broadly repeated over time. Then the correction is made through the progressive and increasingly accentuated use of the economic recession or depression, which is a more or less accentuated brake to the altered or excessive trend of the development rate. Therefore, there would be a univocal meaning regarding the objective we can give to the economy cyclical movement. Consequently, we can argue that the attempt to force the plan of natural evolution through the intemperance of mankind is just a nonsense against nature, a misleading and naive will of arrogance, which can only come out defeated from this unacceptable fight.

This consideration means that even the tools to reduce the damage of the post-speculative recession can be successful in reducing the damage and the social consequences of the serious cyclic inversion. But the fact remains that the bill owed with nature, accumulated for all the errors in the economy management, remains partially to be paid, when there are in place obstacles to the free expression of the natural corrective process.

According to this point of view, the action to curb the effects of the 2008-2010 severe recession, through huge public spending in deficit and new instruments of monetary policy, can only cause a temporary postponement of the correction recessionary mechanism. This mechanism of a partial referral of recessionary effects, through the fiscal support policy, would be the basis of the historical regular occurrence of the speculative process, intended as an instrument of the mechanism regulating the equilibrium for the life survival on the planet.

\section{DISCUSSION}

The suggested hypothesis of a recovery in the speculative situation during the coming years doesn't seem so unlikely. Some similarities between the present situation and the global economy in the first decade seem to be substantial, though the scenario is already changing. The speculative wave in the 2000s on the Real Estate sector and on subprime mortgages has moved following a euphoric trend that involved the whole sector, though without dragging the rest of the economy. Thus, the economic growth trend and the inflation rate remained quiet, enough to simulate an ambiguous condition of relative stability of the economic system in general. According to the past experience, only in the pre-terminal phase of the speculative process has been noticed a rise, in any case controlled, both in GDP and Inflation, which may be the anteroom of a serious financial crisis.

Figures 4 and 5 show the Inflation and GDP profiles in the period 2000-2017 for the main industrialized countries. As we can see, on the eve of the serious crisis the alarm sounds with the acceleration of the inflation rate that in the USA and Europe of 28 is touching $4 \%$ and more than two points higher in China. The GDP profile is also significant: in the USA it reached the highest levels (over 3.50\%) in 2004 and 2005, while it declined by about a point in the following two years until the turning point imposed by the financial crisis in 2008. 
If we accept the hypothesis of a potential new speculative round in the next few years, then it seems useful to keep an eye on the pressure exerted on prices by the eventual formation of a speculative movement. Prices that, in the experience, remained neutral and controlled at around $2-2.5 \%$, to increase until $3-4 \%$ with the maturity of the speculative process. Instead, the GDP trend is more heterodox: at the time in the USA, UK and Japan it touches a maximum of 3.5-4\% with more than two years of advance compared to the end of the speculative process, while in Europe its acceleration follows the speculation increasing rhythm.

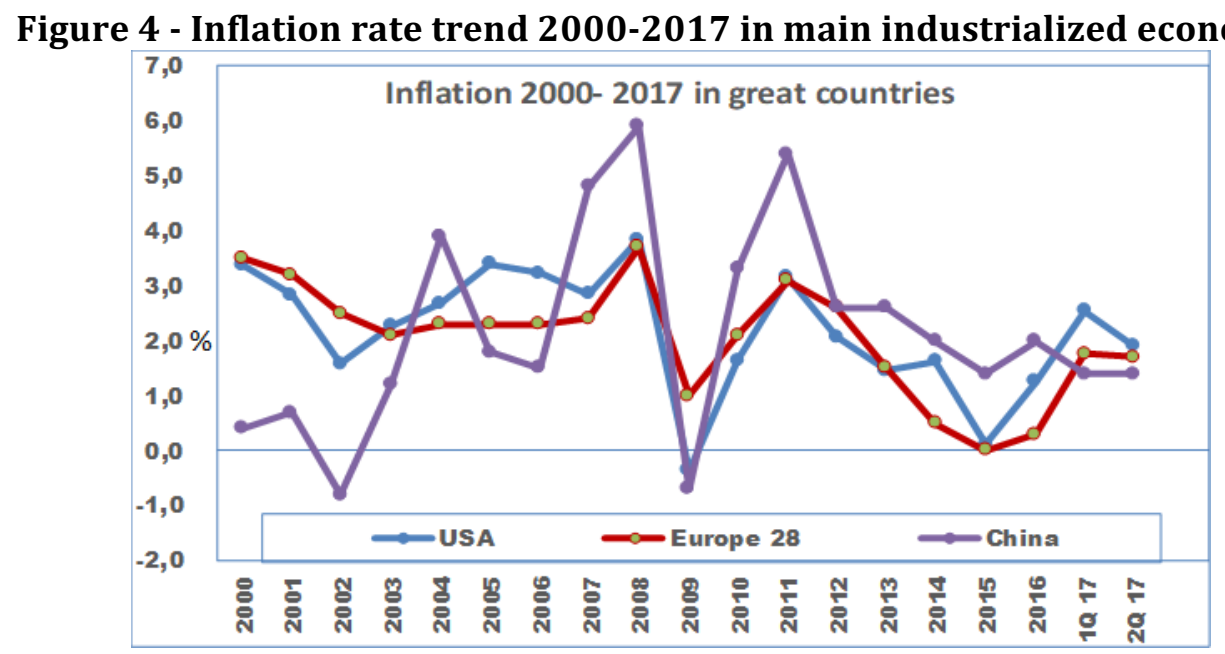

Figure 5 - GDP trend 2000-2017 in main industrialized economies

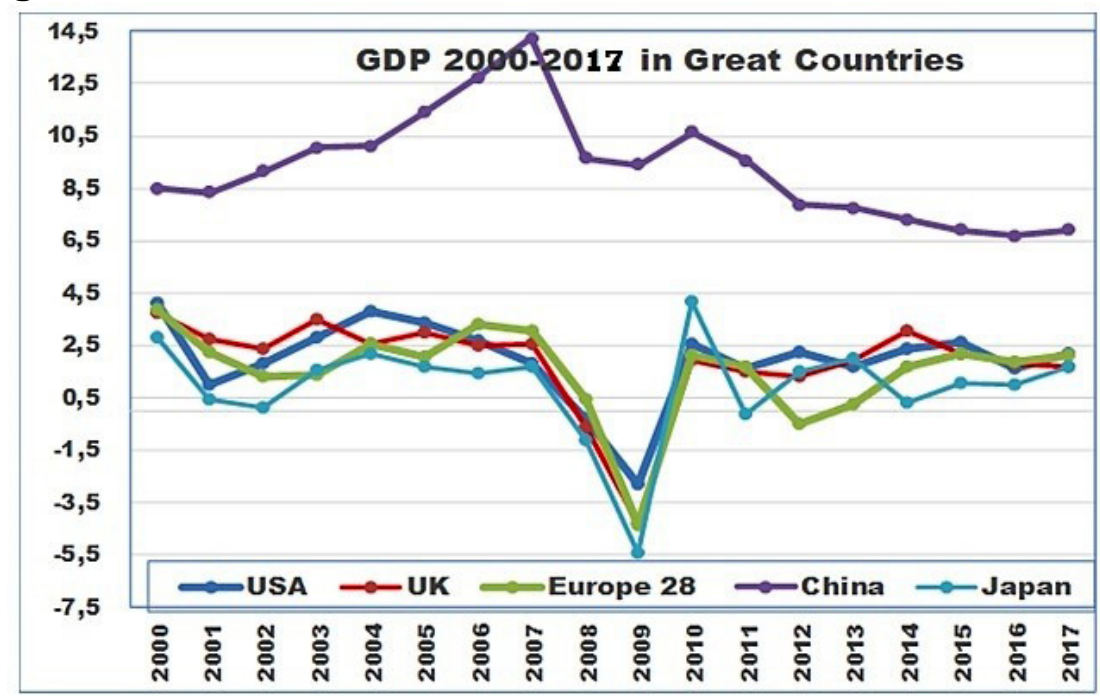

Elaborations on OECD data

In the present situation, I therefore believe that the global economy evolution can be better assessed with a view both to the economic situation cycle and to the parallel evolution of the price curve. In fact, the question under examination is the evolution rhythm asynchrony of the development rate in the major industrialized countries, which can become a critical factor in the eventual round of a new speculative event.

There is no doubt, in fact, that the current situation shows a singular difference from the picture before the 2008-2009 crisis. At the time, the major continental economies were moving in full synchrony, with the European Union and the USA with an average growth of $2.5 \%$ per year and China strongly accelerating until 2007. Moreover, the inflation profile at the time followed a common growth line up to $4 \%$ just before the USA and the European Union recession, while China was instead rising. 
Otherwise, in the current context the relationship between the USA, Europe and China is quite changing. After a 2017 in which the concert of the different continental economies remains somehow balanced in terms of growth, the change is now under way, driven by good commercial relations. There is a differentiation between the USA and Europe in terms of economic development and, consequently, of inflation rate.

Trump's America accelerated in the second quarter, recording an increase of $4.2 \%$ and, prospectively, a 2018 growth of 3.5\% and even more. A performance that could go on for the next two or three years. According to the economist Allen Sinai: "It is difficult to say that Trump can put the exceptional trend of the economic situation as a feather in his cap, Let's say he made the right moves at the right time." 10 The fiscal reform approved a year ago, the federal spending increase on large investments, the ongoing financial deregulation as well as the Fed policy under the management of Janet Yellen, all these actions are giving good results because, according to Sinai, they've been implemented at the right time.

An important success for the US economy during the next two or three years. Subsequently, however, the average growth of the US economy would stay at $1.5 \%$, due to the strong deceleration from 2020-21 onwards. This hypothesis of a galloping economy only for a while, could be somewhat comforting, because in the medium term the perverse effects produced by the acceleration over the American economy actual potential in the next three years would be somehow mitigated.

In other words, the medium-term perspective of a three-year period with some speculative pressures in the US economy, followed by a phase of the growth rate strong deceleration, could firstly feed and then cool the emerging tensions. Consequently, therefore, the American and global economy could be channeled on a more compatible development path.

The artificial acceleration of an economy at continental level, like the USA, is always an indication of a more aggressive exploitation of natural resources and therefore of new instability for the economic system. Conversely, a controlled development line follows a slower pace, and if necessary a corrective inversion of the economic cycle, to mitigate the gap between exploitation and available natural resources.

According to this prospect, the speculative tensions born since 2000 in American territory and then reflected on a global scale, can be an extreme sign of the growing exploitation made by the traditional economy on natural resources and, therefore, of the irrevocable need for the restoration of a relationship compatible with the nature. It follows that the answer to this natural need for compatibility, whenever the economic situation is overcharged, can only be a slow pace of the global economy growth just to mitigate the strength of intensive exploitation. Instead, an alternative response from the economy, moving towards a new phase of accelerated growth, may conflict with the natural obligation to safeguard the common house and the resources of all living beings. Hence the possibility that the artificial acceleration phases of development may start - within a context already unstable for an intensive use of natural resources - a sequence of violent development cycles. That is, a virtual growth series driven by speculation that - once started - is no longer controllable, also for a strange narcosis capturing the operators deceived by the singular normality of economic development $3 \%$ on average) and of inflation, controlled and even low despite the price pressure on raw materials, on oil first.

10 From the interview to Allen Sinai on the newspaper "la Repubblica" of 29 July 2018. 
In the early 2000s, the warning of an artificial growth in American territory came out with the speculation of the so-called dot.com. A parallel can be glimpsed in the price acceleration of technology stocks (FaceBook, Apple, Amazon, Netflix, Google). Since last July, the quotations of these tech-stocks have lost about 350 billion, although they recently returned to the level of two months ago.

It is important not to underestimate these signs of excessive effervescence, especially if the correction would go on. Despite these signals, we cannot say that we are on the verge of a more or less forthcoming reversal of the economic situation in American territory and consequently in the global economy. The euphoria of the markets is not measurable and doesn't alarm due to the strange apathy suffered by the operators in measuring the risk. For the same reason, also the turning point of speculation cannot be predicted.

We could say that in the United States the risk of a new speculative wind would grow if the wealth effect created by the Stock Exchange and the greater availability provided by the Trump presidency's fiscal reform, all together would increase the pressure of an updated speculative process.

However, as demonstrated by the last decade experience, the turning point of a speculative trend may be delayed for a long time, even for years. In any case, both the speculative process and the inflation trend, are requiring an increasing liquidity to continue and this is an excess not related to the real economy. In the inflation case, the continuation would be provided through new currency but with a decreasing value. In the speculative case, the continuation would be assured through the unstoppable production of new liquidity to feed the speculative values, as in the case of subprime mortgages.

This is suggesting that the speculative process, though already started, could nevertheless fall through. In other words, it could have an early end, should the economic situation be suddenly changed due to unexpected events or should the monetary policy management be hardened.

Well, it doesn't seem doubtful that the push of the economic situation through the fiscal channel and the greater public spending for investments can be the catalyst for a new speculative wave in the USA. So, there are good reasons to believe that a sudden cycle exhaustion, expected by 2020-21, and the cumbersome public debt - which could reach in the next few years $90 \%$ in terms of GDP - could cool just in time the new bubble.

Even in the case of an early end of the speculative wave we should expect, however, a downward reaction of the conjuncture. In other words, a recession on the model experimented in 2008-2009 in the USA, because the instability correction, imposed by the irrevocable natural balance, is essentially a forced stop of the natural mechanism of economic development. A break in the development process, to restore the natural control on the consumption of the planet's resources.

From the perspective of the consumption of resources, it seems reasonable to think that the measures adopted during the 2008-2010 recession, to mitigate the economic situation decline, although positive in the short-medium term, were however in contrast with the rationality of the natural order. As saying that the ultra-Keynesian interventions to fight the adverse conjuncture do not solve the problem of the natural order balance. Therefore, at some point the 'bill' will be submitted again, and again according to a natural corrective procedure, which starts - in a sort of cyclical series - speculative waves and recessions. 


\section{CONCLUSION}

Therefore, it doesn't seem unlikely that in the coming years the economic situation in the USA could reverse the route towards recession. Nevertheless, it wouldn't be a natural consequence after a growth decade, according to the cyclic economy theory. The expected recession instead may be an episode of the speculation-recession sequence, as a natural tool to reduce instability and to restore balance in the consumption of natural resources.

In this hypothesis, namely that the propagation of the post-speculative recessive wave would start again from the USA, we can expect a release of the same rebound which, in the 2008-2009 financial crisis, has spread with different intensity within the global economy. Otherwise, the current global economy scenario has changed, so the past crisis picture cannot overlap without changes a future repeat of the financial crisis.

Well, the current scene of the world economy is somehow deeply changed, compared to ten years ago, when the major financial crisis - after the '29 - did burst into the world stage. At the time, the major economies were moving in sync with a moderate development pace. During the formation of the previous speculative bubble, the Western economy has grown on average by $2-2.5 \%$ and only occasionally has reached $3 \%$ or more. A different stress touched the Chinese economy which was rising up to $11 \%$ and more in the imminence of the financial crisis. The present scenario, on the other hand, shows the USA accelerating to exceed $3 \%$ this year, while the EU of 28 is decelerating until just a little over 1.8-2\%. Same situation in 2019 with the forecast close to 3\% for America and below 1.5\% for Europe.

China's behavior is a great enigma. The Asian giant is in slow deceleration and a growth of around $6 \%$ is credited for 2018. Actually, the back-shoring process or the production delocalization in various areas is accelerating, so imposing the progressive substitute growth inside the domestic Chinese market, to balance the declining export of low-cost goods. The protectionist policy initiated by the White House against China seems to play a minor role, though sounding as an alert for the Chinese authorities about the alternative growth program of the internal market. On the other hand, it seems inevitable that, given the maturity reached by the Chinese economy, the development accelerations are now a past legacy.

Well, how will Europe, and China above all, react if the rupture, even premature, of a potential American bubble would start an instability corrective recession in the coming years. It is likely that the US Presidency's anxiety to influence, in its favor, the trend of world trade is pushing the US economy and, consequently, the global economy towards a natural correction of the cycle. In this hypothesis, the reaction of the global economy could be different from the one experienced in the years 2008-2010. 


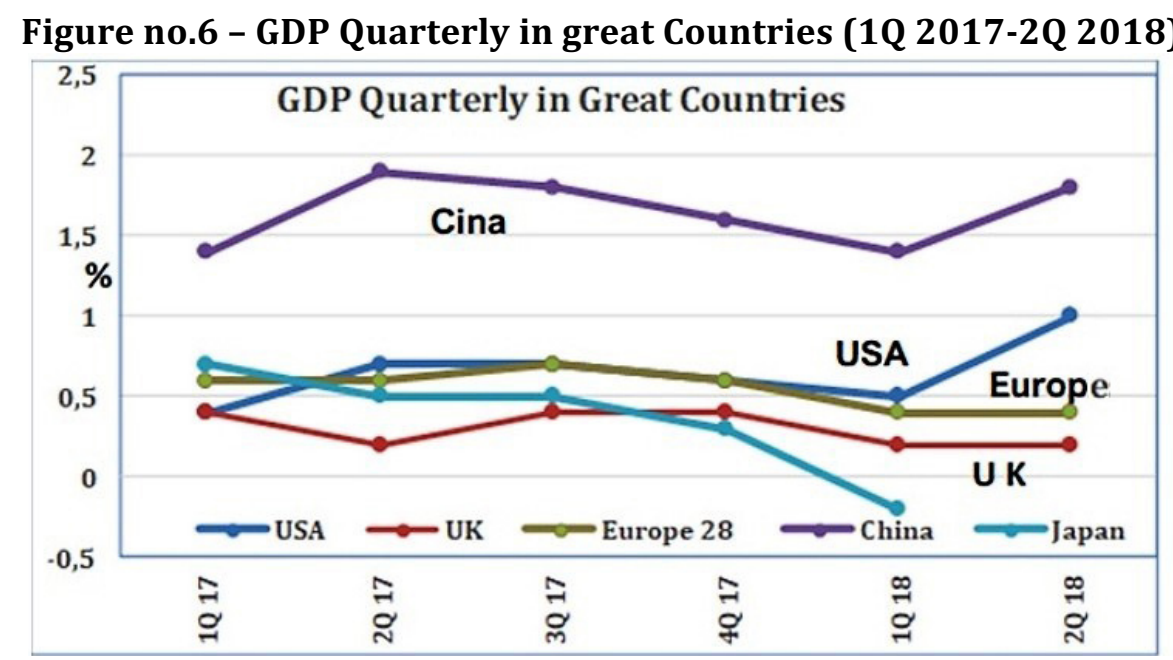

Elaboration on OECD data

The European Union is not following the US economy in its growth path over potential. Instead, the EU proceeds on a more cautious growth path, in order to stay at $1.5 \%$ on average in the two-year period 2019-2020. The inflation rate in the EU, in fact, is expected to be stable and averaging around $1.5 \%$ over the next two years. A more cautious line of development indeed, which in the case of Italy can fall on average under $1 \%$ in the two-year period due to financial weakness, while for France and Germany it is outlined slightly higher also for the limitations on international trade. A non-different destiny is now preparing for Great Britain, struggling with the Brexit from the European Union.

After all, the European continent is moving with great caution on the path of near future growth. An almost stasis that evaporates, whenever present, any speculative tension. Therefore, the conjuncture between the two sides of the Atlantic is now misaligned, differently from the conjunctural concordance experienced in the last decade. We can therefore imagine that the break - even premature - of a speculative bubble in Trump's America would not create a chain of speculative deflagrations in Europe, unlike the previous decade.

A deep recession in the USA, in any case, would have repercussions on the global economy and more particularly on the old continent, for the commercial relations linking the two sides of the Atlantic. The intensity of this recession bounced from the United States could be contained in Europe, thanks to the growing importance of the Union internal market. On the other hand, there is the possible reaction of the US administration to an eventual deep inversion of the cycle. In the experience gained during the previous decade, the United States have applied a strong ultra-Keynesian strategy to cope with the sudden decline of the economic cycle, with an unprecedented recourse to the deficit spending.

In the hypothetical case of a new bubble in the USA and of a severe recession in an undefined future, we should consider that the public debt, equal to about 50\% in terms of GDP in 2007, is now around $85 \%$ and could exceed $90 \%$ in the next three years. The ultra-Keynesian strategy to counter the severe depression in 2008-2009 and, since last year, the fiscal reform and the ongoing investment program are dragging up the country's public debt.

This growing indebtedness could be an important obstacle to a great reissue of an ultraKeynesian strategy, put in place to face a new serious reversal of the US economic cycle. Therefore, the measure of the recession rebound wave in Europe may depend on the attitude chosen by the US Administration to hold out against the eventual next recession and, therefore, may depend on the depth of any corrective cycle in America. 
More complex may be the reaction of China and the satellite economies of Southeast Asia to a possible inversion of the cycle in the speculative post-wave in the USA, accentuated by the growth above potential during the three-year period 2018-2020. In the previous edition of the financial shock that affected the global economy in 2008-2009, China's economy has slowed the accelerated development pace, although the growth in the period 2009-2011 has reached the average of $8 \%$ per annum, but then gradually declined in the following years. This exploit of the Asian giant doesn't seem to be repeatable in the near future, in the situation of a solid recession in America and a slowdown in Europe.

The drive to delocalization dragged by the speculative wave in the USA and Europe along the previous decade has accelerated the economic situation in China in a violent way. When the serious financial crisis occurred, the world's hunger for low-cost Chinese products increased. The potential decline of the Chinese economy has been so contained with the strength of exports, and indeed the still robust progression has continued. Today we are in a different condition. The challenge for the continuation of the Asian economy run is now played on the internal market growth, while it's under way the reverse process of back-shoring or relocation from the Pacific Asia to the European countries of the former USSR and to sub-Saharan Africa.

A phenomenon that will be accentuated during the coming years, therefore allowing to exclude that, in the event of a new crisis in the Western markets, China may still use the defense represented by the river of foreign investments, to mitigate the impact of a corrective crisis. If this escape of the Chinese economy from the wave of the global crisis would be marginal, we may also witness a normalization of its economy after more than twenty years of run. In fact, we cannot rule out that the emphasis of China's incessant economic growth can be concluded by a marked correction, like in the Japan 1990's model, suggested by the slowdown in the world economy.

In fact, it is legitimate to argue that the long run of development in China carried a growing instability or, better, was feeding a prolonged submerged speculative process, which could not come to the surface through a corrective crisis. A crisis stifled by the centralized administration's powerful organizational machine and, above all, by the driving force of industrial relocation inside China's territory, that have created jobs and low-cost production, which have flooded the worldwide market.

An upcoming post-speculative crisis, likely to be started by the growth over potential in the USA, could this time involve the Asian continent in the recessive storm, with unpredictable outcomes and certainly more serious than ever for the general economy. It cannot be excluded, however, that the emphasis of the cyclical turnaround could be mitigated by ultra-permissive monetary policies, by new goals for ultra-Keynesian interventions and by new targets for the public debt. However, the braking of natural corrective action goes against the growth objective compatible with the natural global equilibrium.

\section{References}

Bernanke B. S. - "Essays on the Great Depression” Princeton University Press - Princeton, New Jersey - 2000

T. F. Cargill - "The political economy in Japanese monetary policy” - HUTCHISON, TAKATOSHY Massachusetts Institute of Technology 1997

E. Cardoso - "Inflation and Poverty" in NBER Working Paper \# 4006, year 1992

Cossiga G. A. - "Stability and Instability of an Economic System: Considerations" Review of European Studies - Vol. 9 no. 32017

Cossiga G. A. - "The Search for Inflation on a Constant Basis at 2\%" International Journal of Science, Social Sciences. Vol. X, No. X, 2018, 
Cossiga G. A. "Signals from the World of Economics. The Price Constant and the Democratic Issue" International Journal of Social and Administrative Sciences. Vol. 3, No.1, 1-21 (2018)

Dornbusch, Fischer - “Moderate Inflation.” 1993. World Bank Economic Review 7, 1-44

Geithner T. F. - "STRESS TEST -Reflections on Financial Crises" - RH Business Books

Friedman Milton - “On economics - Selected Papers” (University of Chicago Press, 2007

Kindleberger, C. - “The World in Depression: 1929-1939” University of California Press, 1973

Krugman P. R. - "The return of depression economics and the crisis 2008” W.W. Norton \& Company, New York

Krugman P. R. - "End This Depression Now" - W.W. Norton \& Company, Inc. New York

Krugman P. R. - "Thinking about the liquidity trap” Journal of the Japanese and International Economies (2000)

Inquiry Report - "THE FINANCIAL CRISIS" - Final report of the NATIONAL COMMISSION on the causes of the financial and economic crisis in the United States - Official Edition

L. N. Lindberg, S. Maier, B. Barry - "The Politics of Inflation and Economic Stagnation” - Brookings Institution Washington D.C.

Mirrlees J. A. - “Welfare, Incentives, and Taxation” Oxford University Press (1 June 2006)

Roubini N.- "Crisis Economics: A crash Course in the Future of Finance" - Stephen MIHM

Roubini N., Alesina A., Cohen G. - "Political Cycles and the Macroeconomy"

Raines J. P., Leathers C. G. - "Debt, Innovation and Deflation: The Theories of Fisher, Schumpeter and Minsky”Edward. Elgar Massachusetts

Reinhart C., Rogoff K. S. - “The Time Is Different - Eight Centuries of Financial Folly” Princeton University Press Princeton and Oxford - 2009

Shilling A. G. - "Deflation. How survive and thrive in coming wave of deflation” 2001

Roach S. S.- "The next Asia - Opportunities and challenges for a new globalization" - John Wiley \& Sons, Inc - 2009

Sargent T. J.- "The Ends of Four Big Inflation" in “Inflation: Causes and Effect” University of Chicago Press - Robert Hall Editor

Schumpeter J. - "Business Cycles: A theoretical, historical and statistical analysis of the Capitalist process" New York Toronto London: McGraw-Hill Book Company, 1939

Stiglitz J. E. - "The EURO. How the common money threatens the future of Europe” W. W. Norton \& Company New York London, 2016

Temin P, - “Lessons from the Great Depression” The MIT Press - Cambridge - Massachusetts

Wapshott N. - "KEYNES - HAYEK. The Clash that Defined Modern Economics” - W. W. Norton \& Company - New York - London

Wolff M. - "Fire and Fury. Inside the Trump White House" Henry Holt and Company - New York

IMF and OECD - "International Financial Statistics" - Database, various years - "OECD. Stat" - Database, various years

IMF - World Economic Outlook Update, July 2018

European Central Bank - Press Conference. Mario Draghi, President of the ECB, Luis de Guindos, Vice-President of the ECB, Riga, 14 June 2018

Congressional Budget Office USA - The Budget Outlook for 2018 to 2028

Office of Mediobanca Studies - Cumulative Data of the Main International Banks - (July 2018) 